\title{
Proposed Algorithm For Using GLCM Properties \\ To Distinguishing Geometric Shapes
}

Kifaa Hadi Thanoon

kh.thanoon@gmail.com

Computer Systems

Technical Institute/Mosul

Northern Technical University, Mosul, Iraq

Received on: 16/10/2018

Accepted on: 24/01/2019

\section{ABSTRACT}

In this research, an algorithm was used to look at the characteristics of a set of images for geometric shapes and then to classify them into totals based on four characteristics obtained from the co-occurrence matrix (energy, contrast, correlation and homogeneity).

Studying the above four characteristics in detail and then presenting a complete presentation on the extent of their effect on the distinctive characteristics of the geometrical shapes. The adopted algorithm shows that the above four qualities can be new features of geometric shapes in digital images.

The results of the practical application of the proposed algorithm show that the three features of homogeneity, energy, and contrast give a topical distinction to the shape, but the correlation property is weak in the distinction of shape.

The algorithm was programmed using MATLAB R2010a for Windows 7 operating system on the computer that has the following specifications: (Processor Intel (R) Core (TM) i5, CPU 640 M \& 2.53 GHZ, RAM 6GB).

Keywords: shapes, texture analysis, co-occurrence matrix, feature extraction.

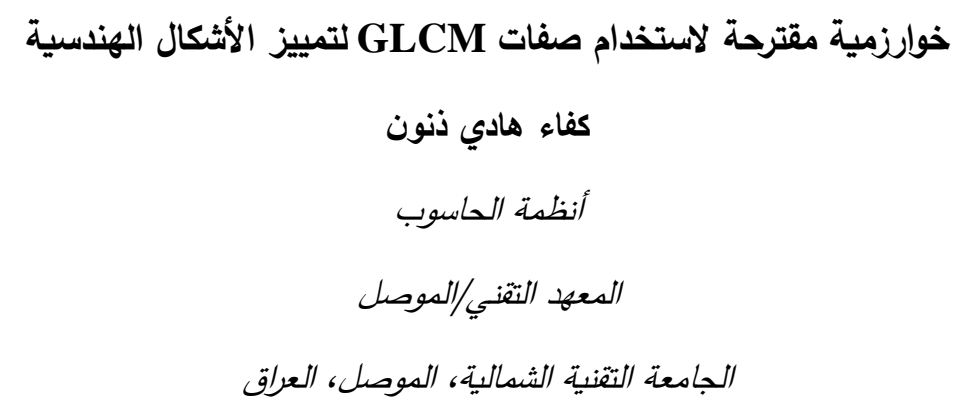

تاريخ قبول البحث: 2019/01/24

تاريخ استلام البحث: 2018/10/16

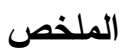

تم في هذا البحث استخدام خوارزمية للبحث في الخصائص المميزة لمجموعة من الصور للأشكال الهندسية،

ومن ثم القيام بتصنيفها إلى مجاميع بالاعتماد على اربعة صفات يتم الحصول عليها من مصفوفة الظاهر المشترك

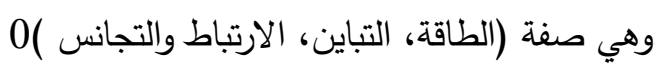




$$
\begin{aligned}
& \text { دراسة الصفات الأربعة المذكورة أعلاه بالتفصيل ومن ثم تقديم عرض كامل عن مدى تأثيرها على } \\
& \text { الخصائص المميزة للأشكال الهندية. والخوارزمية المعتمدة تبين أن الصفات الأربعة المذكورة أعلاه يمكن أن فئن } \\
& \text { تكون خصائص جديدة للأشكال الهندسية في الصور الرقمية. } \\
& \text { تظهر نتائج التطبيق العملي للخوارزمية المقترحة أن الصفات الثلاثة التجانس والطاقة والتباين تعطي تمييزًا } \\
& \text { عالي للثكل بينما خاصية الارتباط ضعيفة في تمييز الثكل. } \\
& \text { تم برمجة الخوارزمية باستخدام (MATLAB R2010a) لنظام التثغيل Windows7) } \\
& \text { الكمبيوتر الذي يملك المواصفات التالية : (Rntel(R) Core(TM) i5 , CPU 640 M \& 2.53 GHZ , } \\
& \text {.(RAM } 6 \text { GB } \\
& \text { الكلمات المفتاحية: الأشكال، وتحليل النسيج، مصفوفة الظاهر المشترك، استخلاص الخواص. }
\end{aligned}
$$

\section{Introduction}

Many of the characteristics of objects in our world can be largely determined by geometric characteristics or features [1]. Therefore, the discovery and extraction of geometric features of digital images are important issues in image analysis and computer vision [2] [3] The purpose of image analysis is often to distinguish shapes such as (circle, ellipse) [4] [5]. The process of detection and differentiation of circles is very important in analyzing the image of objects that contain defined signs and encoded into circles, for example confidential documents marked or sealed to the signal [6] [7]

The Hough Transform technique is used to detect the circle, but there is a problem in its application. One of these problems is to determine the threshold necessary to reduce the values of the accumulators used by the conversion. For example, if the threshold of values entered in the accumulator matrix is very low, Will generate many values, some of which are wrong, and if the value of the threshold is too high, it can not generate enough values to detect the circle [6] . and then developed the HOF conversion technique to detect ellipse, hyperbolic curves and irregular shapes (arbitrary shapes) [8] [9], but requires a memory space A beer or a huge data processing, and as a result there is a lot of wasted time to calculate space data sites [2]

This paper proposes algorithm of the high affectivity characteristics of homogeneity, energy, contrast and correlation for geometric shapes all of which can be obtained from a co-occurrence matrix.

\section{Research Objective}

The main objective of the research is to use a new idea to derive properties of geometric shapes in digital images based on evaluating some morphological properties.

\section{Theoretical Aspects}

\subsection{Shape Representation}

We can classify the shape representation into two categories:

\subsection{1 - The first class represents two ways}

- Contour-based method

- Region-based method

The method of dependence on the ocean [10] [11] of the most common applications because of its compatibility with the human nature, because it only displays information available on the perimeter of the body and thus requires less 
information for storage. The second method depends on the state of the form presented in full or in the form of clips.

\subsection{2 - The second category is represented in two ways:}

- Global approach

- Structural approach

The global method uses the routing property derived from the integral limit to describe the shape in the way of dependence on the ocean. The common characteristics are (area, rotation, deviation, energy curvature, varied circuits, diffuse flood, convex).

The shape in the 2D image can be represented by general features such as (area, perimeter, concentration, inertial torque, Fourier descriptor), or by local character (eg line cut, arc cut, endpoint, etc.) Only the form of the visual image can be described entirely, where as the local character is available exclusively for objects enclosed in the images [3] [12] [13].

\section{Shape Features In The Image}

There are many properties available and used in image classification and retrieval, the most famous of these properties is the property (color, structure, characteristics of the shape)

Characteristics of the shape can be divided into two main groups:

2.1 - Syntactical: which uses structural descriptions suitable for regular forms such as objects made by human beings.

2.2 - Statistic: Which is most suitable for irregular forms, ie, naturally occurring forms.

Statistical characteristics can be obtained by using histogram techniques which are common for their smoothness and smooth performance [14].

In addition to the structure and shape, color image distribution (for gray levels), which are necessary features in the content-based image retrieval (CBIR), the image hierarchy is a first- The histogram describes only the general distribution of colors with the neglect of spatial regulation, this has a significant impact on the efficiency of image retrieval [15] 0 generally should be used in the general distribution of colors in the image, We know a range of properties $\mathrm{T}$ differentiated each body on its own [16] .

\section{Image Feature Extraction}

The visual specifications (such as shape, color, structure) can be drawn to describe the images, each of these characteristics represented by the use of one or more descriptors of the characteristic [17] [18].

There are two effective techniques for deriving characteristics:

3.1 - ASM Active Shape Model: The shape model fits the real picture by using local distortions related to the local variable model.

3.2 - AAM (Active Appearance Model): Integrates the global structure of the most consistent but slower model of ASM, as well as more sensitive to the structure variations and under different lighting conditions. In addition, both ASM and AAM suffer from incorrect convergence when the model starts from A place far from the location of the real body [19]

Part of the systems interested in the process of retrieving the image required from a large group based on the basic characteristics can be drawn automatically from the same images of these systems CBIR system, the algorithms used in these systems are generally divided into three tasks:

a) Extraction 
b) Selection

c) Classification

Extraction converts the important contents of the images into the properties of the different components. The selection of properties reduces the number of properties fitted to the classification process. The properties that are not selected will be neglected. [20] These three tasks are the most critical. Directly on the efficiency of taxonomic functions [17]. ie, a simple improvement of color-based image retrieval using bidirectional statistics, because the two-digit statistical measures use spatial regulation between pairs of dots present or shown in image 0 so correlation-based methods have been used in structural analysis since in 1950 by Kaiser, which was the first to use the self-presence function to measure the roughness of the structure

The co-occurrence matrix was presented by Haraliac as a tool based on contrast in structure analysis. The contrast function was used in the image retrieval field, and Huang relied on chromatic contrast (the way in which spatial variance can be described as a function of distance) [15].

The research included the use of a new idea to derive properties of geometric shapes based on the co-occurrence matrix and to obtain the specifications of this matrix, represented by (energy, contrast, homogeneity, correlation) properties.

\section{Co-occurrence Matrices}

The Co-occurrence matrix is used primarily to describe the texture of the region, but it can also be used in image maps to measure the number of times a two-pixel parameter is given [21]. We can know $r$ the spatial relationship Left, above, etc., Cr Cooccurrence matrix for this relationship $r$ calculates the number of times the pixel where $i$ is valued with the pixel $\mathrm{j}$ by relationship $\mathrm{r}$. The structure characteristics of the gray levels assume that the structure information in the picture contains 18 spatial relationships between the pixel in the image. This is the first parameter of the gray level Co-occurrence matrix. This is a guess or estimate of the potential density function of the second rank of the points in picture, and the characteristics are obtained as statistics from a matrix The GLCM matrix, which is defined by equation (1), has GLCM inputs $(n, m)$ equal to the number of points appearing at grayscale $n, m$ respectively with the separation of (dr, dc) of points figure (1). The number of points on this estimate obtained is given by equation (2). If Co-occurrence matrix normalized taking into account $\mathrm{R}$, then input represents the possibility of the presence of pairs of pixel levels of gray $n, m$ with separation ( $d r, d c)$. We will choose $d c=0$ and $d r$ change between 1 to 10 in column wise [22] [23].

$$
\begin{gathered}
\operatorname{glcm}(n, m)=\sum_{(i, j),(i+d r, j+d c) e R O I} 1_{(I \mathrm{mg}(i, j)=n, I m g(i+d r, j+d c)=m\}} \\
R_{g l e m}=\sum_{(i, j)(i+d r, j+d c) e \text { ROI }} 1
\end{gathered}
$$




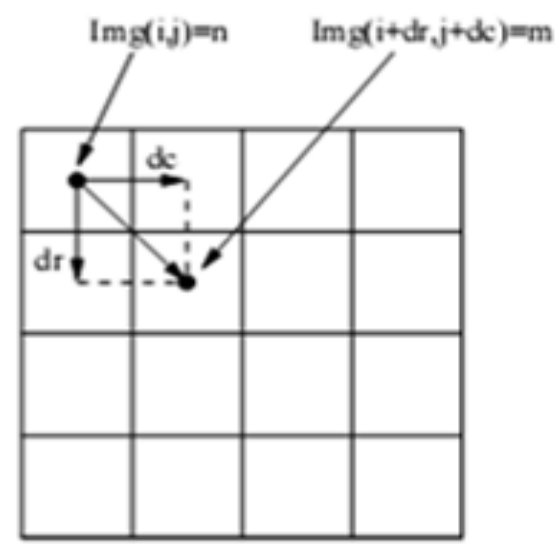

Figure (1) Generation of GLCM(n,m).

\section{Creating a Gray-Level Co-occurrence Matrix}

To configure GLCM, the co-occurrence matrix for gray levels often calculates the intensity of the pixel (gray level) of $\mathrm{n}$ in a spatial relation to a pixel of $\mathrm{m}$, primarily the spatial relationship defined as a pixel of interest and its adjacent pixel horizontally on the right directly, the element $(\mathrm{n}, \mathrm{m})$ produced in the co- occurrence matrix is simply the sum of the number of pixels that have a value of $n$ in the spatial relationship specified for the pixel of $\mathrm{m}$ in the input image. Because processing requires a calculation of the co-occurrence matrix for the full variable range in the image, this is not desirable, so using the measures to reduce the number of density values in gray images from 256 to 8 , the number of gray levels determines the size of the co-occurrence matrix.

The grayscale co-occurrence matrix can reveal some properties about the spatial distribution of gray levels in the image structure. For example, if most of the entries in the co-occurrence matrix are centered along the diameter, the coarse structure takes into account the specified distance [23].

Figure (2) show a clear basic example to generate GLCM matrix.

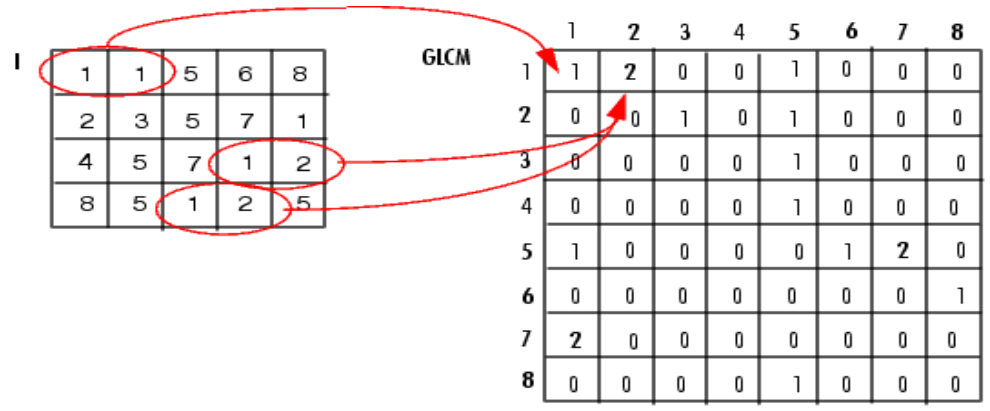

Figure (2) Process Used to Create the GLCM

\section{Description of Two-dimensional Co-occurrence Matrices}

The two-dimensional co-occurrence matrix proposed by Haralik in 1970 is typically used in texture analysis because it is able to take spatial dependence of grayscale values in the image [24]. A 2D co-occurrence matrix $\mathrm{P}$ is a matrix of dimensions $(n, n)$, where $n$ is the number of gray levels in the image. for computational efficiency the number of gray levels can be reduced and thus the size of the cooccurrence matrix is reduced. The matrix is represented as an accumulator, so $P(i, j)$ calculates the number of point pairs that have the intensity $i$ and $j$. points pairs It can be 
represented by a shift vector $d=(d x, d y)$, where $d x$ represents the number of points that travel along the $\mathrm{x}$-axis and dy axis of the number of points that travel along the $\mathrm{y}$-axis in the image slice.

In order to determine this spatial dependence of grayscale values, different properties of the structure must be calculated as suggested by Haralick [24,25,26], including Entropy, Contrast, Maximum Probability, Variance, Energy (Angular Second Moment), Sum Mean (Mean), Homogeneity, Correlation, Inverse Difference Moment, and Cluster Tendency. For the The formulas and descriptions of these characteristics are found in Table (1).

Table (1) The co-occurrence features

\begin{tabular}{|c|c|c|}
\hline Feature & Formula & What is measured? \\
\hline Entropy & $-\sum_{i}^{M} \sum_{j}^{N} P[i, j] \log P[i, j]$ & $\begin{array}{l}\text { Measures the randomness of a gray-level distribution. The } \\
\text { Entropy is expected to be high if the gray levels are } \\
\text { distributed randomly through out the image. }\end{array}$ \\
\hline $\begin{array}{l}\text { Energy(Angular } \\
\text { Second Moment) }\end{array}$ & $\sum_{i}^{M} \sum_{j}^{N} P^{2}[i \cdot j]$ & $\begin{array}{l}\text { Measures the number of repeated pairs. The Energy is } \\
\text { expected to be high if the occurrence of repeated pixel } \\
\text { pairs is high. }\end{array}$ \\
\hline Contrast & $\sum_{i}^{M} \sum_{j}^{N}(i-j)^{2} P[i . j]$ & $\begin{array}{l}\text { Measures the local contrast of an image. The Contrast is } \\
\text { expected to be low if the gray levels of each pixel pair are } \\
\text { similar. }\end{array}$ \\
\hline Homogeneity & $\sum_{i}^{M} \sum_{j}^{N} \frac{P \mid[i \cdot j]}{1+|i-j|}$ & $\begin{array}{l}\text { Measures the local homogeneity of a pixel pair. The } \\
\text { Homogeneity is expected to be large if the gray levels of } \\
\text { each pixel pair are similar }\end{array}$ \\
\hline SumMean (Mean) & $\frac{1}{2} \sum_{i}^{M} \sum_{j}^{N}(i P[i, j]+j P[i, j])$ & $\begin{array}{l}\text { Provides the mean of the gray levels in the image. The } \\
\text { SumMean is expected to be large if the sum of the gray } \\
\text { evels of the image is high. }\end{array}$ \\
\hline Variance & $\frac{1}{2} \sum_{i}^{M} \sum_{j}^{N}\left((i-\mu)^{2} P[i, j]+(j-\mu)^{2} P[i, j]\right)$ & $\begin{array}{l}\text { Variance tells us how spread out the distribution of gray } \\
\text { evels is. The Var iance is expected to be large if the gray } \\
\text { evels of the image are spread out greatly. }\end{array}$ \\
\hline Correlation & $\sum_{i}^{M} \sum_{j}^{N} \frac{(i-\mu)(j-\mu) P[i \cdot j]}{\sigma^{2}}$ & $\begin{array}{l}\text { Provides a correlation between the two pixels in the pixel } \\
\text { pair. The Correlation is expected to be high if the gray } \\
\text { evels of the pixel pairs are highly correlated. }\end{array}$ \\
\hline $\begin{array}{l}\text { Maximum Probability } \\
\text { (MP) }\end{array}$ & $\stackrel{M, N}{\operatorname{Max}} P[i, j]$ & $\begin{array}{l}\text { Results in the pixel pair that is most predom inant in the } \\
\text { mage. The MP is expected to be high if the occurrence of } \\
\text { the most predominant pixel pair is high. }\end{array}$ \\
\hline $\begin{array}{l}\text { Inverse Difference } \\
\text { Moment (IDM) }\end{array}$ & $\sum_{i}^{M} \sum_{j}^{N} \frac{P[i \cdot j]}{|i-j|^{k}} i \neq j$ & $\begin{array}{l}\text { nverse Difference Moment tells us about the smoothness } \\
\text { of the image, like homogeneity. The IDM is expected to } \\
\text { be high if the gray levels of the pixel pairs are similar. }\end{array}$ \\
\hline Cluster Tendency & $\sum_{i}^{M} \sum_{j}^{N}(i+j-2 \mu)^{k} P[i, j]$ & $\begin{array}{l}\text { Measures the grouping of pixels that have similar gray } \\
\text { evel values. }\end{array}$ \\
\hline
\end{tabular}

\section{Proposed Algorithm}

The proposed algorithm has the potential to find the characteristics of various geometric shapes (circle, polygon, square, ellipse, triangular) and irregular shapes in different dimensions ranging from $(50,50),(100,100)$, .. to $(300,300)$ To extract the four qualities mentioned previously for retention and then apply the same steps on new forms in order to extract the four attributes adopted in the research to compare with what was obtained previously to determine the form that was tested.

Figure (3) represents a schematic schema for the operation of the algorithm proposed in this research 


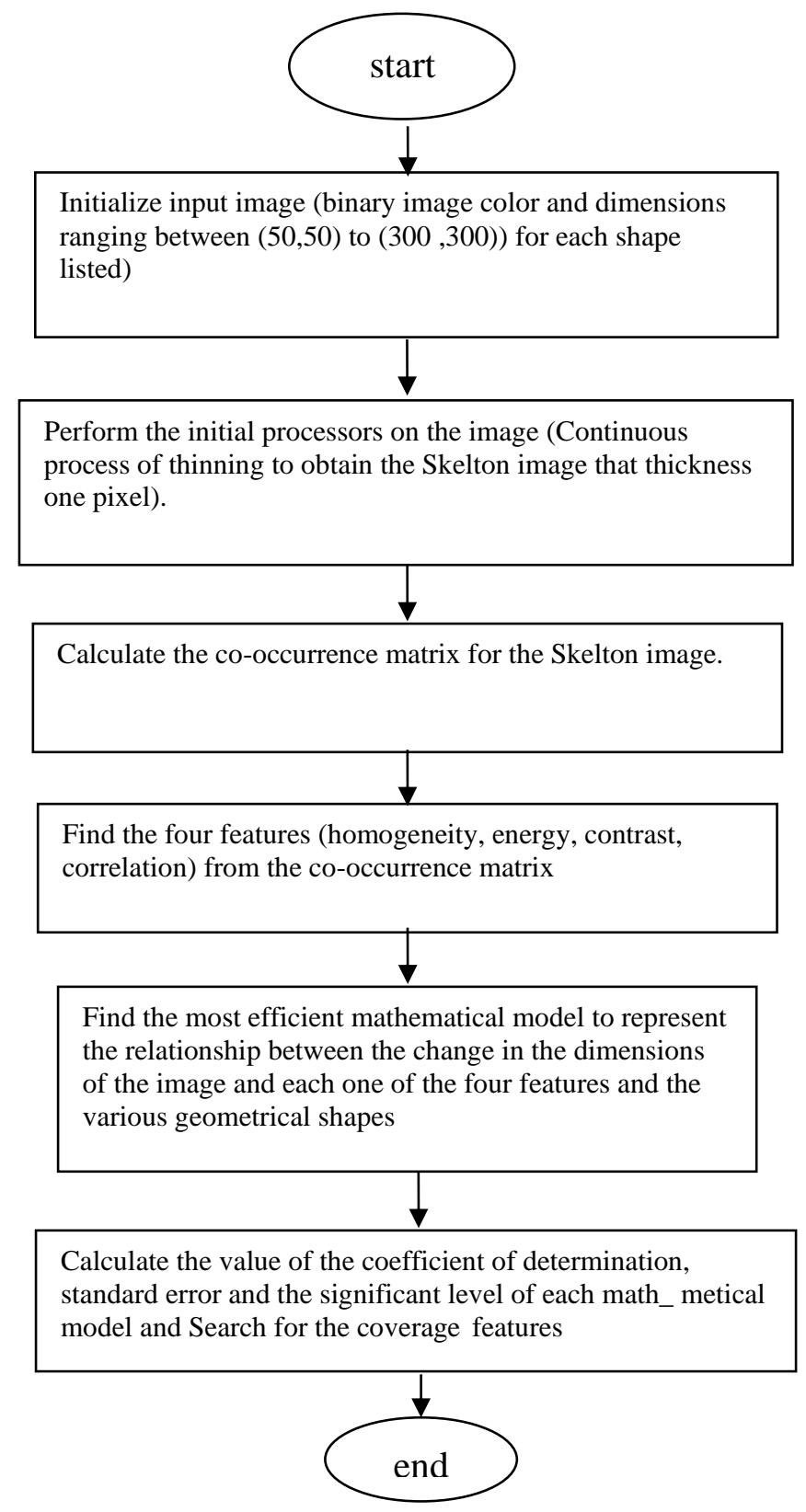

Figure (3) represents a schematic diagram of the proposed algorithm

\section{Result Discussion}


After applying the proposed algorithm to geometric shapes and with different dimensions, the following values, shown in Tables $(2,3)$, show the extent of the effect of each of the four attributes on changing the dimensions of the geometrical image.

Table (2) The four properties of geometric shapes with varying dimensions of the image.

\begin{tabular}{|c|c|c|c|c|c|}
\hline shape & $\begin{array}{l}\text { Size } \\
\text { imag }\end{array}$ & Contrast & Correlation & Energy & Homogeneity \\
\hline \multirow{6}{*}{$\stackrel{0}{\Xi}$} & 50,50 & 0.0718 & 0.2165 & 0.8416 & 0.9641 \\
\hline & 100,100 & 0.0368 & 0.2589 & 0.915 & 0.9816 \\
\hline & 150,150 & 0.0258 & 0.2559 & 0.9403 & 0.9871 \\
\hline & 200.200 & 0.0192 & 0.2471 & 0.9557 & 0.9904 \\
\hline & 250,250 & 0.0156 & 0.2577 & 0.9637 & 0.9922 \\
\hline & 300,300 & 0.0129 & 0.2703 & 0.9695 & 0.9935 \\
\hline \multirow{6}{*}{ 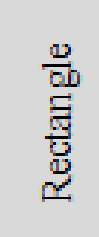 } & 50,50 & 0.0637 & 0.4628 & 0.8219 & 0.9682 \\
\hline & 100,100 & 0.0372 & 0.471 & 0.8939 & 0.9814 \\
\hline & 150,150 & 0.0251 & 0.4845 & 0.927 & 0.9875 \\
\hline & 200.200 & 0.019 & 0.4883 & 0.9442 & 0.9905 \\
\hline & 250,250 & 0.0154 & 0.4874 & 0.9547 & 0.9923 \\
\hline & 300,300 & 0.0128 & 0.4922 & 0.9622 & 0.9936 \\
\hline \multirow{6}{*}{ 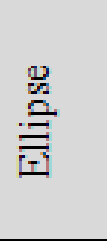 } & 50,50 & 0.0376 & 0.5204 & 0.8856 & 0.9812 \\
\hline & 100,100 & 0.0206 & 0.5083 & 0.9379 & 0.989 \\
\hline & 150,150 & 0.0141 & 0.5052 & 0.9575 & 0.9929 \\
\hline & 200.200 & 0.0122 & 0.4608 & 0.9654 & 0.9939 \\
\hline & 250,250 & 0.0102 & 0.4447 & 0.9715 & 0.9949 \\
\hline & 300,300 & 0.0085 & 0.4498 & 0.9762 & 0.9958 \\
\hline \multirow{6}{*}{$\frac{\overrightarrow{8}}{8}$} & 50,50 & 0.0657 & 0.3389 & 0.8392 & 0.9671 \\
\hline & 100,100 & 0.0337 & 0.3525 & 0.9153 & 0.9831 \\
\hline & 150,150 & 0.025 & 0.3459 & 0.9375 & 0.9875 \\
\hline & 200.200 & 0.0182 & 0.3339 & 0.9548 & 0.9909 \\
\hline & 250,250 & 0.0151 & 0.3383 & 0.9624 & 0.9925 \\
\hline & 300,300 & 0.0126 & 0.3142 & 0.9691 & 0.9937 \\
\hline \multirow{6}{*}{ 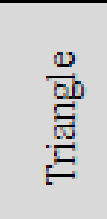 } & 50,50 & 0.0669 & 0.2871 & 0.8436 & 0.9665 \\
\hline & 100,100 & 0.0356 & 0.3176 & 0.9136 & 0.9822 \\
\hline & 150,150 & 0.0251 & 0.3174 & 0.9389 & 0.9875 \\
\hline & 200.200 & 0.0188 & 0.3262 & 0.9537 & 0.9906 \\
\hline & 250,250 & 0.0153 & 0.3228 & 0.9624 & 0.9924 \\
\hline & 300,300 & 0.0128 & 0.3261 & 0.9683 & 0.9936 \\
\hline \multirow{6}{*}{ 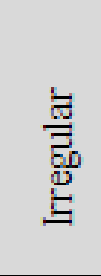 } & 50,50 & 0.0732 & 0.2614 & 0.8331 & 0.9634 \\
\hline & 100,100 & 0.0352 & 0.2747 & 0.9176 & 0.9824 \\
\hline & 150,150 & 0.0238 & 0.2591 & 0.9446 & 0.9881 \\
\hline & 200.200 & 0.0178 & 0.2846 & 0.9555 & 0.9907 \\
\hline & 250,250 & 0.0156 & 0.2878 & 0.9627 & 0.9922 \\
\hline & 300,300 & 0.0127 & 0.3081 & 0.969 & 0.9936 \\
\hline
\end{tabular}

Table (3) Measured values of the coefficient of determination, Standard Err and the calculated significant level of the geometric shapes. 


\begin{tabular}{|c|c|c|c|c|}
\hline Feature & shape & Coff. de ter. & Std_Err & Sig. \\
\hline \multirow{6}{*}{ 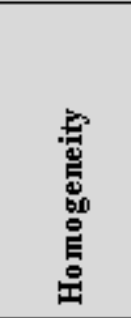 } & Circle & 094 & 00028 & 0,003 \\
\hline & Rectangle & 097 & 0,003 & 0.001 \\
\hline & Ellipse & 095 & 0.003 & 0.001 \\
\hline & Polyen & 094 & 0.003 & 0,002 \\
\hline & Triangle & 095 & 0.003 & 0,002 \\
\hline & Inegular & 092 & 0,003 & 00003 \\
\hline \multirow{6}{*}{ 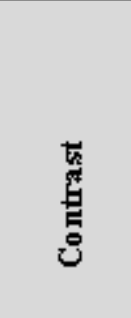 } & Circle & 099 & 0,0020 & 0,003 \\
\hline & Rectangle & 099 & 0,002 & 0001 \\
\hline & Ellipse & 099 & 0,002 & 0006 \\
\hline & Polyen & 099 & 0002 & 0,007 \\
\hline & Triangle & 099 & 0,002 & 0,003 \\
\hline & Inegular & 099 & 0,002 & 001 \\
\hline
\end{tabular}

\begin{tabular}{|c|c|c|c|c|}
\hline \multirow{6}{*}{ 点 } & Circle & 095 & 0003 & 0.01 \\
\hline & Rectangle & 097 & 0.003 & 0000 \\
\hline & Ellipse & 094 & 0.003 & 0008 \\
\hline & Polyen & 095 & 0,000 & 0.01 \\
\hline & Triangle & 095 & 0,003 & 001 \\
\hline & Inegular & 092 & 0,003 & 001 \\
\hline \multirow{6}{*}{ 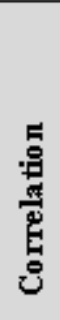 } & Circle & 0.67 & 0,0029 & 001 \\
\hline & Rectangle & 094 & 0,000 & $\overline{0002}$ \\
\hline & Ellipse & 088 & 0000 & 001 \\
\hline & Polyen & 082 & 0002 & 001 \\
\hline & Triangle & 082 & 0,002 & 0006 \\
\hline & Inegular & 060 & 0,002 & 001 \\
\hline
\end{tabular}

By studying the relationship between the dimensions of the image is estimated in pixels with homogeneity feature and after testing a set of polynomial equations found that the logarithmic model was the most efficient $(\mathrm{Y}=0.0162 \ln (\mathrm{x})+0.9039))$, where the coefficient of determination $(\mathrm{R} 2=0.94)$ and a standard error of $($ Std_Err $=0.002)$ and the significant level $(\mathrm{Sig}=0.003)$, indicating the efficiency of the graphic representation of this relationship, ie that $94 \%$ of the changes in the feature of homogeneity due to the change in dimensions of the image and $6 \%$ attributed to other factors not measured. As a result of the high coefficient of determination and the reduction of the standard error value, the logarithmic equation is considered efficient in the graphic representation of the independent factor (image dimensions) in the values of the dependent factor (image homogeneity feature) as shown in figure (4). 


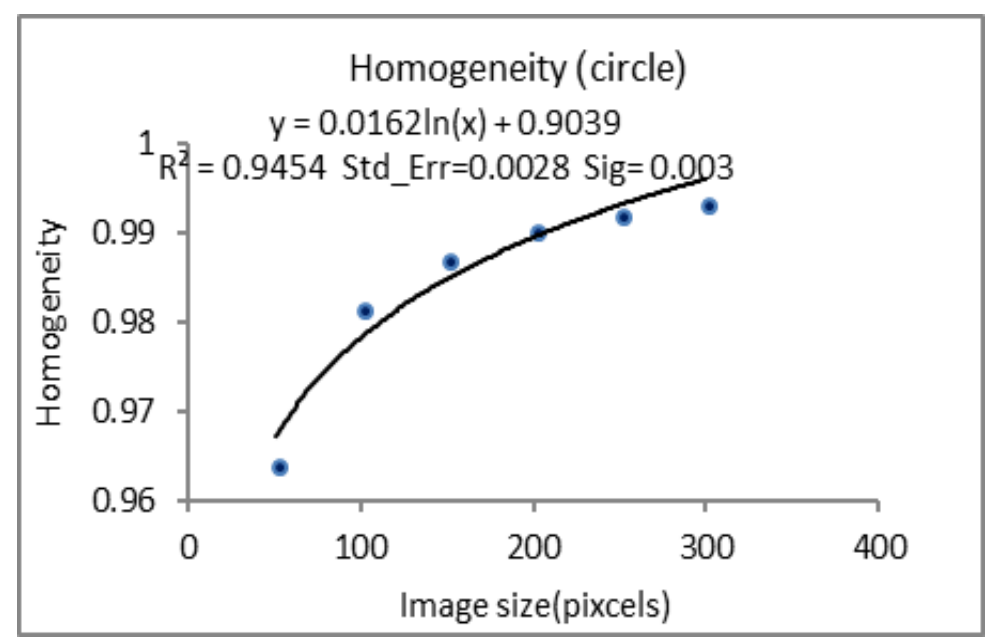

Figure (4) The effect of image dimensions is estimated by pixel in the values of the homogeneity feature of the image geometric shape

As shown in Figure (5) to study the effect of the change in the dimensions of the image is estimated in pixels in contrast feature and when applying a set of polynomial equations found that the most powerful model is the power model $(y=2.986 . X-0.952)$ where the relationship is reversed, Increasing the dimensions of the image results in a lack of contrast in the image. The coefficient of determination $(\mathrm{R} 2=0.99)$ and the standard error (Std_Err $=0.002)$ and the significant level $($ Sig $=0.003)$, indicating the efficiency of the representation of the graph. Where $99 \%$ of the changes that occur The value of the variance is due to the change in the dimensions of the image and $1 \%$ due to other factors not measured as shown in figure (2).

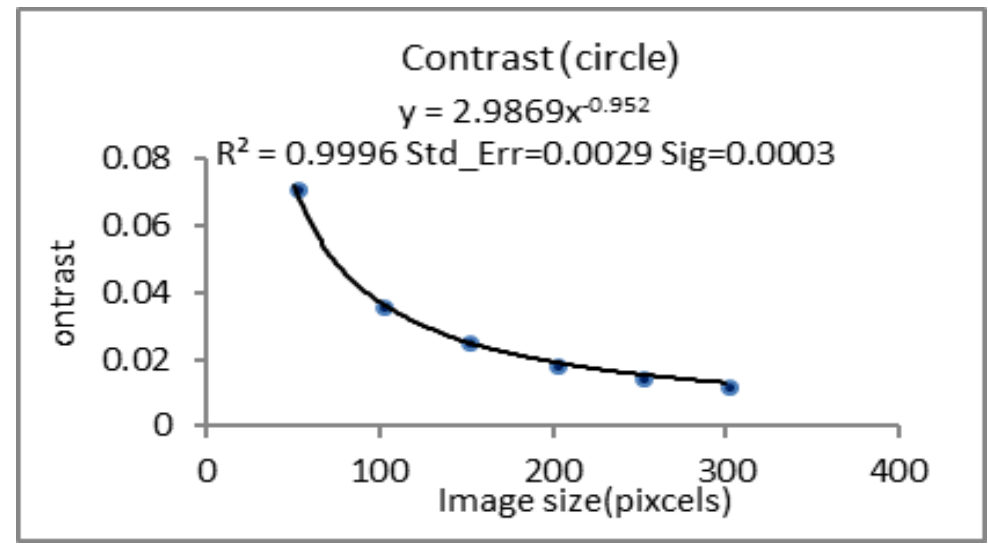

Figure (5) The effect of image dimensions is estimated by pixels in the contrast feature values of the image geometric shape.

As for the relationship of the energy feature with the dimensions of the image and after the adoption of a set of equations was found that the logarithmic model is the best model in the representation of this relationship ( $\mathrm{y}=0.0707 \ln (\mathrm{x})+0.5769)$, where the coefficient of determination $(\mathrm{R} 2=0.95)$ and the standard error $($ Std_Err $=0.003)$ and with the significance level ( $\mathrm{sig}=0.01$ ), ie, the ratio of the effect of changing the dimensions of the image to the energy values of $95 \%$ and $5 \%$ of the remaining changes is due to other factors that are not measured. It is highly efficient in the graphic representation of the effect of the independent factor to dimension the image in the 
energy values of the image Between the values calculated using the relationship and the real values of the energy feature and Figure (6) shows the degree of compatibility.

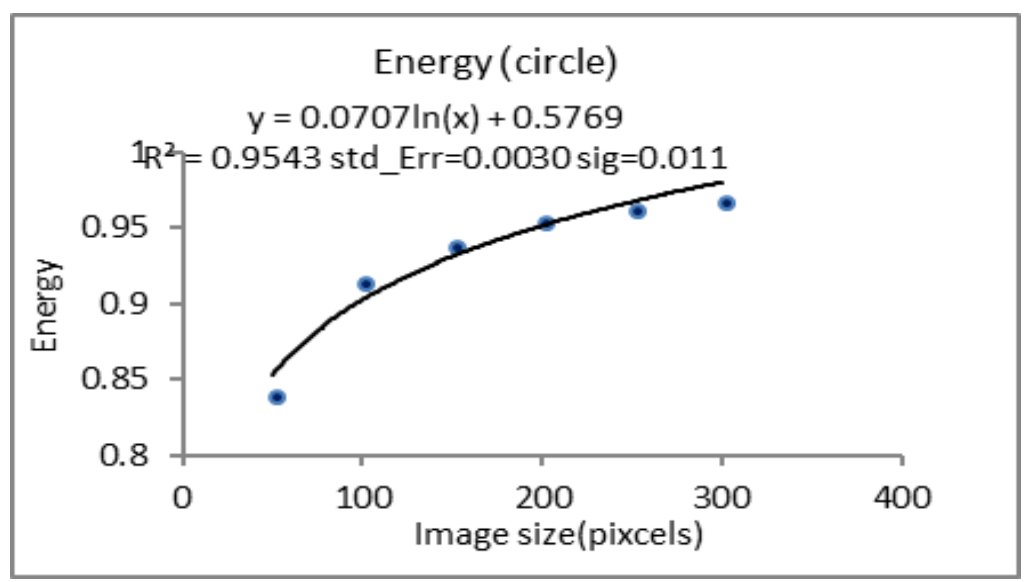

Figure (6) The effect of image dimensions is determined by pixels in the energy values of the image geometric shape

When you study the relationship of the correlation feature to the change in the dimensions of the image and after the application of several equations, the logarithmic model was found to be more efficient to represent this relationship ( $y=0.0229 \ln (\mathrm{x})$ $+0.1361)$. The coefficient of determination $(\mathrm{R} 2=0.67)$ and standard error $($ Std_Err $=$ 0.002 ) with a significant level of ( $\mathrm{sig}=0.01$ ). The percentage of the effect of the image dimensions in the correlation values of the image was $0.67 \%$ and $33 \%$. As a result of the low coefficient of determination, this feature is weak affected to change the dimensions of the image as shown in Figure (7)

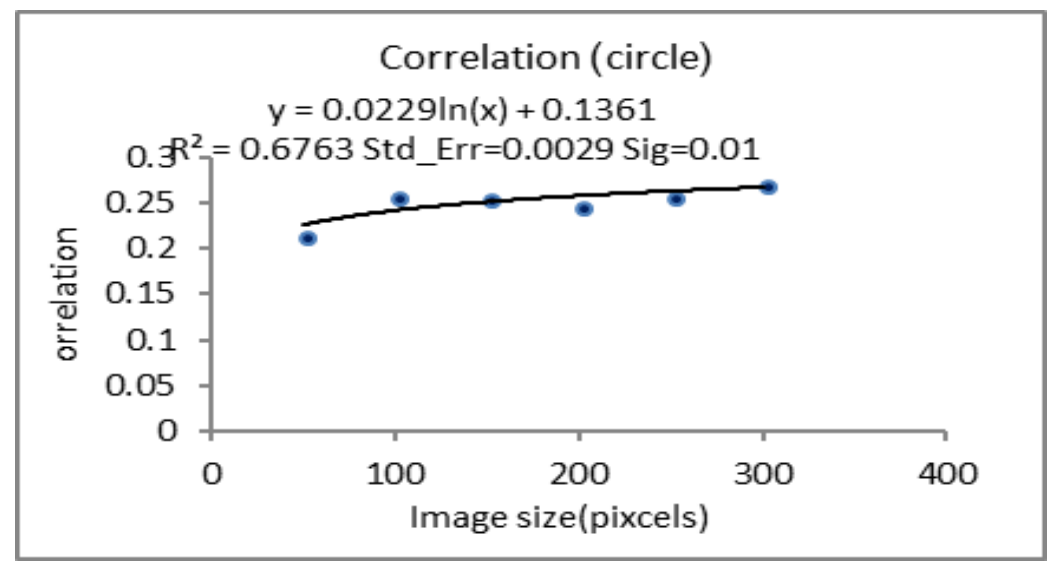

Figure (7) The effect of image dimensions is determined by pixels in the correlation feature values of the image geometric shape

In the above discussion, we conclude that energy and homogeneity features are affected by large changes in image dimensions. The contrast feature is inversely affected. The correlation 42feature, however, is weak as the dimensions of the image change. The three features of homogeneity, energy, and contrast give a topical distinction to the shape, but the correlation property is weak in the distinction of form.

The results in Table (2) and Table (3) in Appendix A, respectively, show the values of the four features of the geometric shapes, the measured values of the coefficient of 
determination, standard err and significant level of the four properties, are drawn in the appendix B.

\section{Recommendations and future work}

1- Connect-based algorithm to distinguish the shapes in the classification of maps drawn by AutoCAD software.

2- The possibility of characterization of the ideas adopted for the physical in order to distinguish to some parts of the human form of discrimination, such as palm or face shape.

3- The possibility of applying the idea of the discovery of angles within geometric shapes for measurement based on the mathematical relationships.

\section{Appendix A}
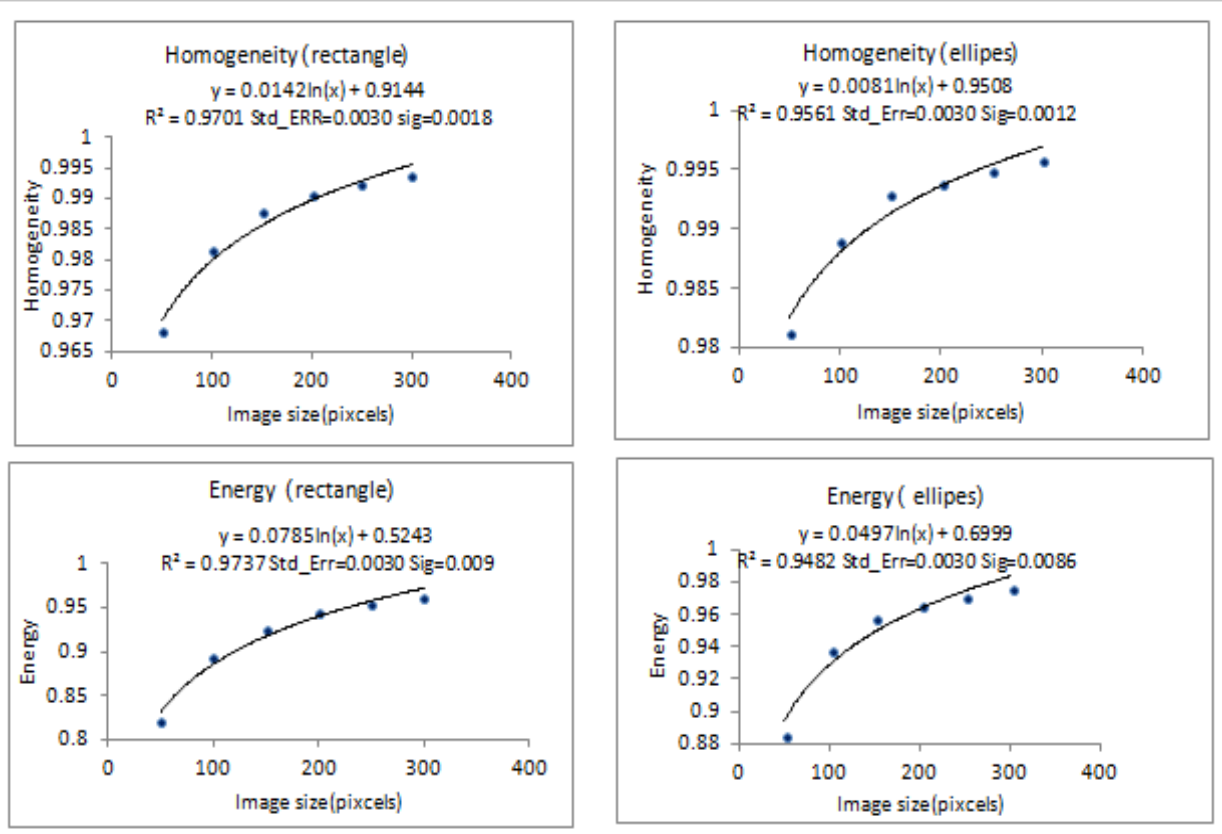

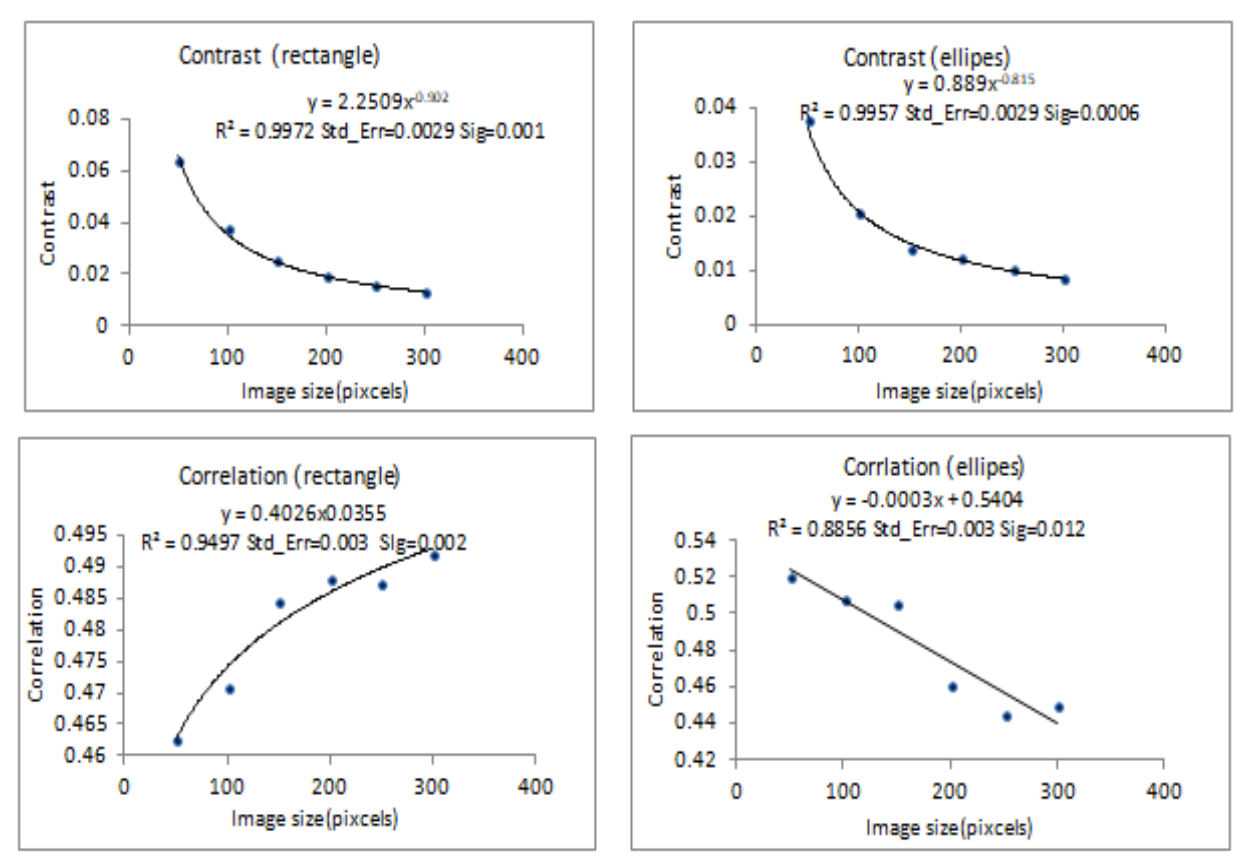

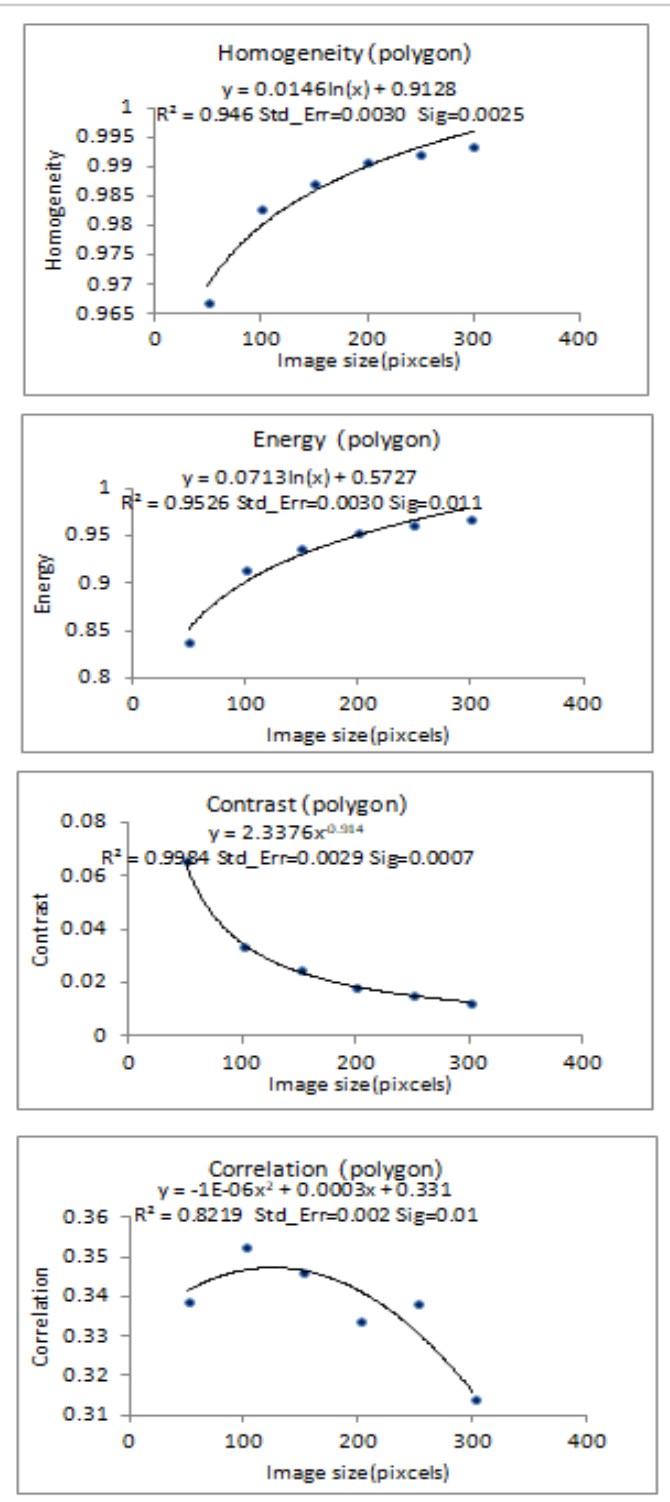
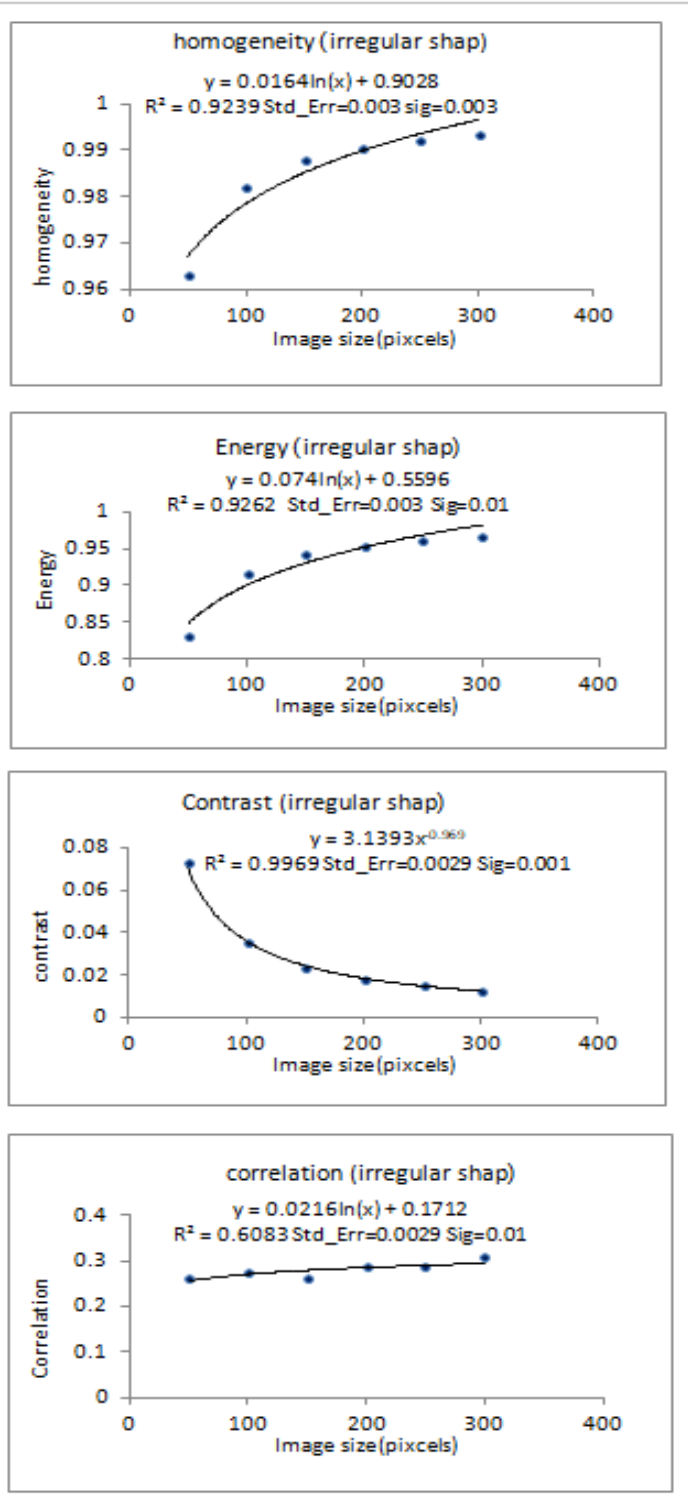


\section{REFERENCES}

[1] Robert M Haralick, K Shanmugam, Its'hak Dinstein, "Textural Features for Image Classification", IEEE Transactions on Systems, Man, and Cybernetics SMC-3 (6): 610-621,1973.

[2] Yu,Wing Hong W, "Memory -Efficient Circle and Ellipse Detection Algorithm in Digital Images", Dept.of Industrial and Manufacturing Systems Engineering, university of Hong Kong, IEEE International conference, Volume 44, ,Pages 4262 - 4267,1995.

[3] S.Saurav, R. Ranjan and M.Kumar, "Color and Shape Recognition", Department of Computer Science and Engineering National Institute of Technology Rourkela,2015.

[4] David M. Mount,Nathan S.Netanyahu,"ellipses, Computational Geometry", Volume 19, Issue 1,Pages1-33, June,2001.

[5] Teh-chuan and kuo-liang chung,"An Efficient Randomized Algorithm for Detecting Circles", Department of Information Management, Institute of Computer Science and Information Engineering, National Taiwan University of Science, 4 March, 2002.

[6] Patents, "system and method for the detection of a circle image for pattern recognition", 1 February,2000.

[7] S.Rege, R.Memane, M.Phatak, P.Agarwal,"2D Geometric Shape And Color Recognition Using Digital Image Processing", Dept. of E\&TC Engineering, PVG's COET, Pune, Maharashtra, India, International Journal of Advanced Research in Electrical, Electronics and Instrumentation Engineering Vol. 2, Issue 6, June, 2013.

[8] R.K.K.Y ip, P. K. S. Tam, D.N.K. Leung, " modification of Hough transform for circle and ellipses detection a 2-dimensional array",Pattern Recognition 25 1007-1022, 1992.

[9] V.Kumar, S.Pandey, A.Pal, S.Sharma, "Edge Detection Based Shape Identification ",Department of Electronics and Communication Engineering Dehradun Institute of Technology Dehradun, India, Computer Science Computer Vision and Pattern Recognition, 2016.

[10] S. Loncaric, "A survey of shape Analysis Techniques, NEC Research Institute",1998.

[11] A.Stubendek and K.Karacs, " Shape Recognition Based on Projected Edges and Global Statistical Features", Faculty of Information Technology and Bionics, Pázmány Péter Catholic University, Prater 50/A, Budapest 1083, Hungary, Mathematical Problems in Engineering Volume 2018, Article ID 4763050, 18 pages ,https://doi.org/10.1155/2018/4763050 .

[12] Kang, Lichun, Lim, Kah Bin," Image recognition of occluded objects based on improved curve moment invariants", Journal of Digital Information Management Article, Volume 7, No.3, Pages 52-158, 2009.

[13] Dinesh Dileep Gaurav, "Feature Extraction for Character Recognition ",1 Dec, 2009.

[14] R. Rout korpi, J.livarinen,"Conture co-occurrence matrix - Anovel Statistical Shape Descriptor", Helsink university of Technology, Laboratory of computer and information Science, P.O.Box 5400, FIN-02015 Hut, Finland, LNCS 3617.PP.253-260, 2005. 
[15] Iivari Kunttu1, Leena Lepistö1, Juhani Rauhamaa2, and Ari Visa1," Binary Co-Occurrence Matrix in Image Database Indexing" 1 Tampere University of Technology, Institute of Signal Processing, 2 ABB Oy, Paper, Printing, Metals \& Minerals, Automation, P.O. Box 553, FIN-33101 Tampere, Finland, P. O. Box 94, FIN-00381 Helsinki, Finland, 2003.

[16] Andrew Fitzgibbon,"Interactive vision binary image processing", the Department of Artificial Intelligence, University of Edinburgh, 2005.

[17] Ryszard S. Chora's," Image Feature Extraction Techniques and Their Applications for CBIR and Biometrics Systems", Inernational Journal of Biology and Biomedical Engineering, Issue 1, Vol. 1, 2007.

[18] M.Ahmadi, M.Palhang. and N.G,"4D implicit shape model for rotation invariant contour-based object detection", Electrical and Computer Engineering Department, Isfahan University of Technology, IEEE Xplore Iranian Conference of Machine vision and Image Processing (MVIP), 2017.

[19] Fei Zuo, Peter H. N.,"Fast facial Feature extraction using a deformable shape model with haar-wavelet based local texture attributes", Eindhoven Univ. of Technol., Depart. EE , LogicaCMG/Eindhoven Univ.of Technol..5600MB Eindhoven, The Netherlands P.O.Box 7089, 5605JB Eindhoven, NL, 2004.

[20] IEEE computer,"Special issue on Content Based Image reterival" ,28,9, 1995.

[21] Clausi, David A,"An analysis of co-occurrence texture statistics as a function of gray level quantization", Can. J. Remote Sensing; Vol. 28, No.1, pp. 45$62,2002$.

[22] Rose F. Walker, Paul Jackway, I. D. Longstaff, "Improving co-occurrence matrix feature discrimination", proceedings of DICTA '95, pp.643- 648, 1995.

[23] Howard D., Mark B., "Neural Network Toolbox User's Guide", The MathWorks, Inc, 2008.

[24] Roberto M. Cesar Junior, Luciano da Fontoura Costa, " Shape analysis and Classification",http://www.ime.usp.br/ cesar/shape_crc, 2001.

[25] Haralick, R.M. and L.G. Shapiro, "Computer and Robot Vision", AddisonWesley Publishing Co, 1992.

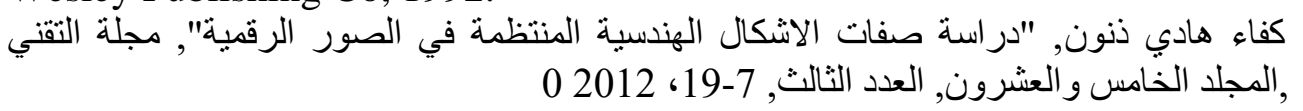

